\title{
Contrasting functional responses of non-native invasive species along a tropical elevation gradient
}

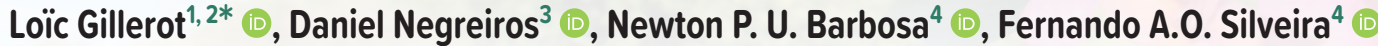 \\ and Luiza F. A. de Paula ${ }^{4}$
}

Received: January 14, 2021

Accepted: October 5, 2021

\begin{abstract}
One hypothesized invasion strategy ("try-harder") predicts that invaders exhibit functional traits that are better adjusted to the environment than native species. Alternatively, the "join-the-locals" hypothesis predicts trait convergence between invasive and native species due to environmental filtering with increasing resource limitation. We hypothesized that invasions strategies shift from "try-harder" to "join-the-locals" with increasing elevation. We used an elevational gradient to detect possible trait convergences between alien invaders and native plant species in Asteraceae, Fabaceae and Poaceae. We found a significant trait convergence with elevation only in Asteraceae, suggesting a species-specific pattern, but also an important phenotypic variability of the alien invader. This supports the idea that the more resource-limited the environment, the more it filters out traits substantially diverging from the locally-adapted native community, thereby entailing a shift from "try-harder" to "join-the-locals" strategies. The invasive grass was also more acquisitive but did not exhibit any relation to the native community, supporting the "try-harder" hypothesis. The size of the invasive Fabaceae species decreased with elevation, mirroring the native Fabaceae species, but not the overall native community. Including more replicates and a thorough quantification of environmental conditions, offers a promising avenue for improving the understanding the seemingly idiosyncrasies of invasion pathways.
\end{abstract}

Keywords: campo rupestre, invasive plants, join-the-locals, OCBIL, plant functional traits, resource-limitation, try-harder

\section{Introduction}

Plant ecological strategies, which can be quantified using a wide array of functional traits, can help to understand the invasion process (Drenovsky et al. 2012). Invasive plants are often ruderals, characterized by traits related to a high resource acquisition efficiency (i.e., fast-growing, shortlived plants with large leaf areas and low leaf dry matter contents, rapidly colonizing disturbed lands) (Grime 2001;
Reich 2014). Trait-based theories have been proposed to describe the invasion strategies of alien species in native communities. On the one hand, the "try-harder" hypothesis states that invaders would present traits that are better adjusted to the local environment than native species, be the conditions benign or harsh (Tecco et al. 2010). On the other hand, traits are expected to converge between invasive and native species as a result of to environmental filtering according to the "join-the-locals" hypothesis (Tecco et al.

1 Forest \& Nature Laboratory, Department of Environment, Ghent University, 9090, Gontrode, Belgium

2 Division of Forest, Nature and Landscape, Department of Earth and Environmental Sciences, KU Leuven, 3001, Leuven, Belgium

3 Instituto de Ciências Biológicas e Saúde, Centro Universitário UNA, 30130-180, Belo Horizonte, MG, Brazil

4 Departamento de Genética, Ecologia e Evolução, Universidade Federal de Minas Gerais, 31270-901, Belo Horizonte, MG, Brazil

* Corresponding author: loic.gillerot@ugent.be 
2010). There is now mixed support for both hypotheses (Tecco et al. 2010; Dainese \& Bragazza 2012; De Paula et al. 2015), which probably reflects the idea that they represent two ends of an ecological continuum (Siniscalco \& Barni 2017; El-Barougy et al. 2020).

Despite the widespread belief that low nutrient availability generally impedes biological invasions (Daehler 2003; Seabloom et al. 2015), various studies reported invasions in infertile landscapes, including mountains (Funk et al. 2013; De Paula et al. 2015). This includes the Brazilian campo rupestre, a megadiverse montane grassland with a highly rocky, nutrient-impoverished substrate that harbours more than 5000 plant species, nearly $15 \%$ of Brazil's plant diversity (Silveira et al. 2016). Native species from campo rupestre are adapted to low-fertility soils, but sites where the disturbance regime has been strongly altered such as along paved roads become rapidly invasion-prone (Barbosa et al. 2010). Other anthropogenic disturbances include mining, soil overfertilization, extensive cattle ranching, logging and urban expansion, among others (Silveira et al. 2016). This study system represents an ideal model to test the functional ecology of plant invasions in infertile landscapes along an elevational gradient, which may help to identify crucial management strategies (Funk et al. 2013).

Our objective was to test how both hypotheses (jointhe-locals vs. try-harder) hold when studied along an environmental gradient in campo rupestre vegetation. We hypothesize that, in line with the "try-harder" hypothesis, alien invaders will show a more acquisitive strategy under less stressful conditions (mountain bottom) relative to the native community. The "join-the-locals" hypothesis would contrastingly be valid under harsher conditions (mountaintop) due to environmental filtering of locally less advantageous traits (contrasting predictions made by El-Barougy et al. 2020). Accordingly, we compared variation in functional traits between non-native invasive and native species from distinct plant families along an elevation gradient to test whether traits converge with increasing environmental harshness.

\section{Materials and methods}

An elevational gradient was selected at Serra do Cipó, the southern part of the Espinhaço range in south-eastern Brazil ( $\left(9^{\circ} 17^{\prime} \mathrm{S}, 43^{\circ} 35^{\prime} \mathrm{W}\right)$. Five $10 \times 10 \mathrm{~m}$ plots were set up every 100 elevational meters along a single paved road covering a range of elevations between 950 and $1350 \mathrm{~m}$, comprising most of the elevational gradient at the study site (Silveira et al. 2019). Plots were selected according to the location closest to the ideal elevation with a cooccurrence of three invasive species (see selection details below), which were kept constant over plots. Previous research in the same area found a trend of decreasing soil fertility (particularly decreasing potassium and clay concentrations and increasing aluminium saturation) with increasing elevation (Coutinho et al. 2015). Our elevational gradient comprises $400 \mathrm{~m}$, but has been shown to be sufficient to drive variation in abundance and diversity across a wide range of organisms (Silveira et al. 2019). Elevation gradients are usually narrower in ancient, and weathered landscapes (Hopper et al. 2021), compared to relatively young, glaciated mountains in the northern hemisphere. The selection of sites and species was done based on a previous study which recorded the occurrence of alien invasive species in 17 sites along the same highway road (Barbosa et al. 2010; Silveira et al. 2019). As the abundance of alien invasive species decreases sharply with increasing distance from the road (Barbosa et al. 2010), plots were set up within 20 $\mathrm{m}$ of the road. In each plot, we sampled native and alien invasive plants belonging to some of the most common and species-rich families of the region (Silveira et al. 2016): Asteraceae, Fabaceae and Poaceae, all occurring both as very common native and alien species (Giulietti et al. 1987; Barbosa et al. 2010; Silveira et al. 2016; 2019). For each family, we selected the most invasive species of the whole gradient, based on their frequency and relative abundance on plots previously sampled along the same transect: Cyrtocymura scorpioides (Lam.) H. Rob. (Asteraceae), Stylosanthes guianensis (Aubl.) Sw. (Fabaceae) and Melinis repens (Willd.) Zizka (Poaceae). By sampling the same invasive species on each plot on the gradient, we were able to study intra-specific variation in traits across the elevation gradient. Note that $M$. repens originates from southern Africa, while the two other species do naturally occur in Brazil. However, they are not native from campo rupestre and were thus considered alien species in the context of this study (Mannetje 1977; Santos et al. 2008; Barbosa et al. 2010; Silveira et al. 2019). In each plot, five individuals of each alien invasive species were sampled, as well as one individual of each native species of the same family co-occurring in the plot to control for phylogeny and within-site variation. This was chosen to compare the functional traits of a single alien invasive species with the mean traits of the native community (in each plot, we sampled from three to seven native species in the same family of the invasive species; see Table S1 in supplementary material for the full list of included native species), while balancing the number of compared individuals (five individuals per invader per elevation compared to, on average, five individual native species). Alien invaders were thus replicated at each elevation, natives were not, but sampling instead focused on capturing the variation and mean of the community and potential intraspecific trait variation in the invaders.

In the field, we measured plant height and sampled three leaves from each individual, which were collected and stored in sealed, moisturized and cooled plastic bags to avoid loss 
of turgor (Pérez-Harguindeguy et al. 2013). Sampling was done at the end of the rainy season in March 2018, when leaves were fully mature. We estimated five leaf functional traits: leaf area (LA), leaf dry matter content (LDMC), specific leaf area (SLA), leaf thickness and leaf toughness within two days after fieldwork (Perez-Harguindeguy et al. 2013). LA was obtained using the software ImageJ (version 1.44; Abràmoff et al. 2004) on scans of fresh leaves. Also using fresh leaves, thickness was measured using a digital micrometer (Mitutoyo series 293, precision of 0.0001 $\mathrm{mm}$ ) and toughness using a digital penetrometer with a cone-shaped tip (Chatillon model DFE-010, Florida, USA). Afterwards, leaves were oven-dried for $72 \mathrm{~h}$ at $60^{\circ} \mathrm{C}$ and then immediately weighted with an analytical scale (precision of $0.01 \mathrm{mg}$ ) to calculate LDMC and SLA.

To test the hypothesis that plant functional traits of alien invasive species converge towards those of the native community when conditions become more limiting for growth, we compared the variation in traits along an elevational gradient. Linear models were used to quantify this variation and to statistically test the presence of an eventual trait convergence with increasing elevation. First, a PCA was rendered with the six traits as variables (Fig. S1 in supplementary material). LA, leaf toughness and thickness needed a log-transformation, while LDMC, SLA and plant height needed to be squared to reach the normal distribution assumed by PCA. The resulting first two principal components ( $\mathrm{PC} 1$ and $\mathrm{PC} 2$ ) were then extracted and used as response variables in linear models. The main multiple linear regression models included elevation, species origin (native/alien - as a categorical variable) and the interactions between those two variables. Because additional analysis found differences according to the plant family, models were repeated for each family separately, complementing the models that compared each invader with the whole native community. Similar models were also made with all six traits as predictors separately. All statistical analyses were performed using $\mathrm{R}$ version 3.5.3 using the package 'stats' (R Development Core Team 2019) while 'ggplot' was used to create graphs (Wickham 2016).

\section{Results and discussion}

The PCA effectively grouped the six variables along its first two components, which respectively explained $37.94 \%$ and $26.51 \%$ of all variation (Fig. S1 in supplementary material). The $\mathrm{PC} 1$ axis was correlated to traits related to the leaf economics spectrum (SLA, LDMC and leaf toughness) (Reich 2014), while the PC2 axis was related to plant size (height, LA and leaf thickness). After using those principal components as response variables, the linear models initially seemed to indicate an overall convergence among plant origins for PC1 (Fig. S2 and Tab. S2 in supplementary material). However, this trend was mostly explained by $C$. scorpioides (Fig. 1). The interaction term (origin:elevation) was indeed only significant for Asteraceae $(p=0.01)$ (Tab. 1 ), supporting the hypothesized traits convergence with elevation and thereby supporting the "join-the-locals" hypothesis. The p-value becomes even smaller when comparing C. scorpioides to native Asteraceae only ( $p=$ 0.002 , see Tab. S3 and Fig. S3 in supplementary material). This result seems to suggest that more resource-limited environments filter out traits substantially diverging from the locally-adapted native community from this family (Waddell et al. 2020).

The substantial shift in traits of $C$. scorpioides suggests an important intraspecific variation (Kichenin et al. 2013), possibly indicating that phenotypic variability is a key characteristic for alien invasive species to naturalize into novel habitats, in cases where phenotypic variability is linked to increased fitness compared to native species (Davidson et al. 2011; Richards et al. 2006). Invaders can thrive under a large range of environmental conditions thanks to morphological and physiological plasticity (Rejmanánek 2000; but see Palacio-López \& Gianoli 2011), which allow them to outcompete native species under both favorable and suboptimal growing conditions (Sultan 2001; Davidson et al. 2011).

In contrast, the invasive Poaceae M. repens also has a consistently more acquisitive strategy over the whole gradient (Fig. 1), although no convergence towards the native community was observed. The lack of convergence observed towards the native community supports the "try-

Table 1. Summary statistics for multiple linear regression models with plant origin (invasive or native), elevation and an interaction term as predictor variables and the two first principal components (PC1 and PC2) as response variables, comparing each invader with the native community (Asteraceae, Fabaceae and Poaceae together). F values are listed together with significance levels denoted as follows: ${ }^{*} p<0.05 ;{ }^{* *} p<0.01 ;{ }^{* * *} p<0.001$. See Table S3 in supplementary material for an analogous comparison with the native plant community separated by families.

\begin{tabular}{|c|c|c|c|}
\hline & Origin & Elevation & Origin:Elevation \\
\hline$P C 1_{\text {cscorpioides }}$ & $98.26^{* * *}$ & 0.15 & $6.93^{*}$ \\
\hline$P C 2_{\text {cscorpioides }}$ & $11.86^{* * *}$ & 0.39 & 1.78 \\
\hline$P C 1_{\text {Sguianensis }}$ & 1.92 & 1.95 & 1.29 \\
\hline$P C 2_{\text {Sguianensis }}$ & $11.43^{* *}$ & $8.00^{* *}$ & $4.83^{*}$ \\
\hline$P C 1_{\text {Mrepens }}$ & $25.76^{* * *}$ & 2.00 & 1.13 \\
\hline$P C 2_{\text {Mrepens }}$ & $56.79^{* * *}$ & 3.49 & 0.49 \\
\hline
\end{tabular}


harder" hypothesis. However, this finding is in contrast with the idea that herbaceous species usually "join-the-locals" and woody species "try-harder" (Tecco et al. 2010; see Tab. S4 in supplementary material for predictor effects on each plant trait separately). In line with our results, De Paula et al. (2015) compared functional traits of the alien invader $M$. repens and the native community in a resource-limited flora (granite outcrops) and found that the invader was functionally distinct from the native community, with traits more related to ruderalism, such as higher SLA and lower leaf area, thus also providing support for the "try-harder" hypothesis. The same authors hypothesize that invasion by this species could lead to the exclusion of certain functional traits in the native community, which could provide an alternative explanation for observed contrast in traits. Such conclusions require sensible control conditions without the invaders' presence, which should be taken into account in future studies.
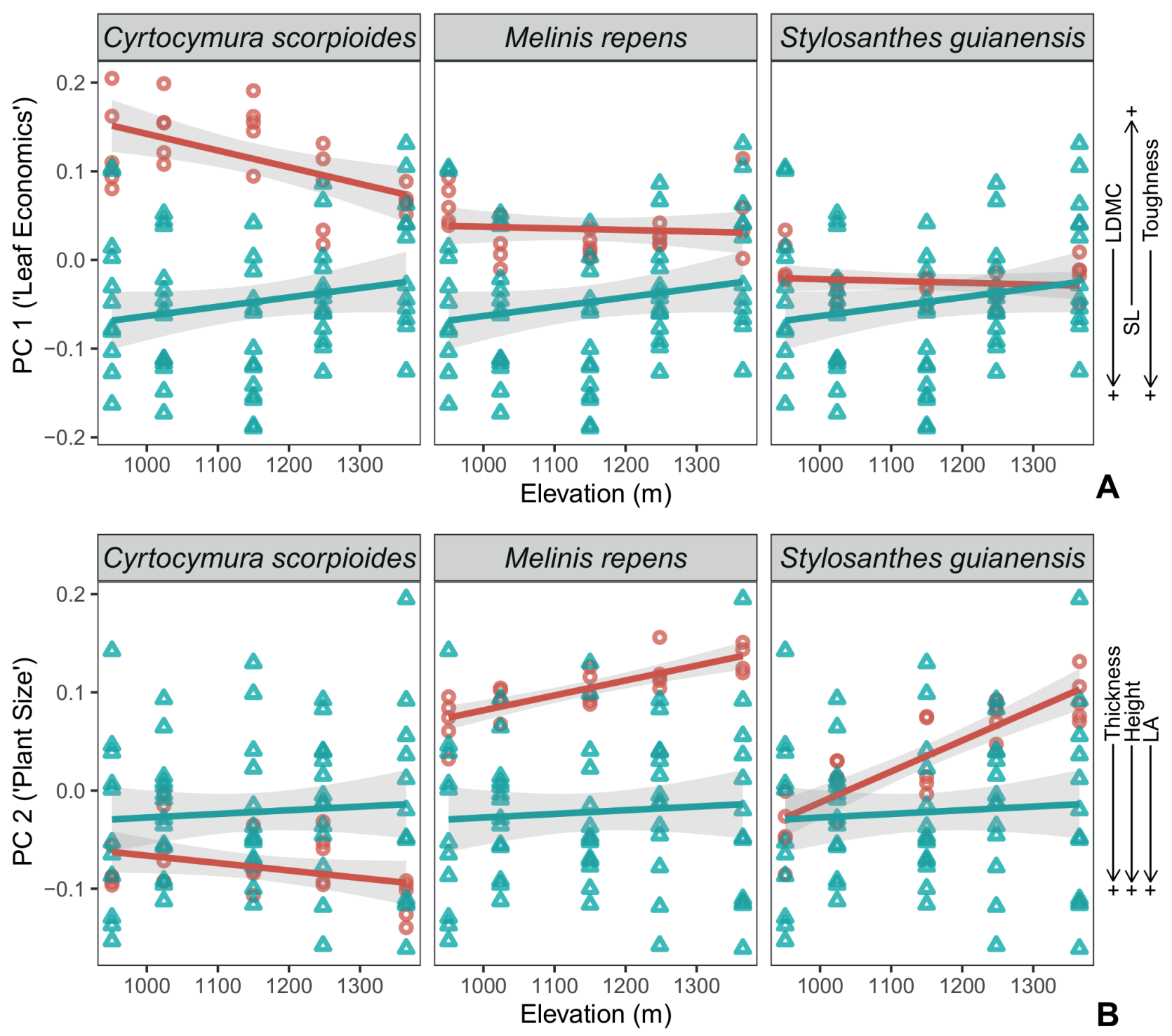

\section{Invasive $\cong$ Native}

Figure 1. Elevational trends in plant functional traits for non-native invasive and the native community (Asteraceae, Fabaceae and Poaceae together). PC1 (A) was used as a variable summarizing the variation in traits related to the leaf economics spectrum (SLA = Specific Leaf Area, LDMC = Leaf Dry Matter Content, and leaf toughness). PC2 (B) was used as a variable summarizing the variation in traits related to plant size (plant height, LA = Leaf area, and leaf thickness). Grey shaded areas represent the standard error. Linear models were run for each invader with elevation, plant origin (invasive/native) and an interaction term as predictors. See Table 1 for more details on significance levels of model predictors and supplementary Fig. S3 in supplementary material for an analogous comparison with the native community separated by families. 
Barbosa et al. (2010) showed that roads catalyse the invasion of alien species into pristine infertile landscapes on the same elevational gradient. The disturbance regime is very important in this type of environment (Hopper et al. 2021), especially because local plant communities grow slowly (Dayrell et al. 2018) and may be outcompeted by invasive species. Our results suggest that invasions in more stressful conditions might also be affected by the invader's capacity to mimic functional traits of the native community, as predicted by the join-the-local hypothesis, and supported by recent studies (Siniscalco \& Barni 2017; El-Barougy et al. 2020). This could, however, be highly species-dependent, as the studied invasive Poaceae species $M$. repens appeared to rather match the "try-harder" hypothesis.

Reasons why observed patterns are species-dependent warrant further investigation. Another unexplained pattern is the increased resource acquisition strategy in native plants with elevation (Fig. 1), contrary to the expected trend towards stress-tolerance generally expected for the resource-limited campo rupestre (Negreiros et al. 2014; Dayrell et al. 2018). This unexpected pattern is present for traits related to the leaf economics spectrum (PC1), but not when using traits related to plant size (PC2, Fig. S1). Edaphic factors may play an important role, since it was shown that soil properties are drastically altered during the paving of the road along which the elevational gradient set up, likely benefiting invasive species (Barbosa et al. 2010). Since fire often temporarily increases soil fertility, it is likely that invasive species, especially the most resourceacquisitive ones, will thrive with increasing fire frequency. Thus, avoiding roadside fires could prevent the further spread of invasive species in nutrient-poor ecosystems. Finally, S. guianensis seems to unexpectedly exhibit a diverging pattern compared to the native community ( $p$ $<0.05$, see Fig. 1), but -unlike the analogous pattern in C. scorpioides- not when considering only native Fabaceae (Fig. S3 in supplementary material). Here, the invading species shows decreased size with elevation as in the native Fabaceae community, while the native community does not show a clear trend. Future research may thus benefit from incorporating more explanatory power by increasing replication and measuring co-varying environmental conditions. To incorporate the potential influence of biotic interactions such as competition, species abundance data could further improve results robustness.

Nonetheless, despite the small number of replicates, we were able to find a highly significant converging trend of functional traits within one of the three studied families, which are representative of the local communities. The use of elevational gradients provides a promising method to understand what drives the adoption of different invasion strategies in function of environmental conditions and how trait plasticity may lead to rapid evolution and invader success in novel environments (Gurevitch et al. 2011).

\section{Acknowledgements}

We are grateful to N. Koedam, L. O. Azevedo, D. Sanín and GSG for their logistic support. We thank R. M. Burkowski, L. O. Azevedo and P. L. Viana for their assistance during botanical identifications and the members of the Laboratory of Tropical Plant Ecology and Evolution for their helpful comments on preliminary results. This work was supported by the Belgian Leopold III Fund for nature research and conservation. FAOS thanks grants from CNPq. LFAP thanks grants from CAPES (88887.569558/2020-00).

\section{References}

Abràmoff MD, Magalhães PJ, Ram SJ. 2004. Image processing with ImageJ. Biophotonics International 11: 36-42.

Barbosa NPU, Fernandes GW, Carneiro MAA, et al. 2010. Distribution of non-native invasive species and soil properties in proximity to paved roads and unpaved roads in a quartzitic mountainous grassland of southeastern Brazil (rupestrian fields). Biological Invasions 12: 3745-3755.

Coutinho ES, Fernandes GW, Berbara RLL, et al. 2015. Variation of arbuscular mycorrhizal fungal communities along an altitudinal gradient in rupestrian grasslands in Brazil. Mycorrhiza 25: 627-638.

Daehler CC. 2003. Performance comparisons of co-occurring native and alien invasive plants: implications for conservation and restoration. Annual Review of Ecology, Evolution, and Systematics 34: 183-211.

Dainese M, Bragazza L. 2012. Plant traits across different habitats of the Italian Alps: a comparative analysis between native and alien species. Alpine Botany 122: 11-21.

Davidson AM, Jennions M, Nicotra AB. 2011. Do invasive species show higher phenotypic plasticity than native species and, if so, is it adaptive? A meta-analysis. Ecology Letters 14: 419-431.

Dayrell RL, Arruda AJ, Pierce S, et al. 2018. Ontogenetic shifts in plant ecological strategies. Functional Ecology 32: 2730-2741.

Drenovsky RE, Grewell BJ, D’Antonio CM, et al. 2012. A functional trait perspective on plant invasion. Annals of Botany 110: 141-153.

El-Barougy RF, Elgamal I, Rohr RP, et al. 2020. Functional similarity and dissimilarity facilitate alien plant invasiveness along biotic and abiotic gradients in an arid protected area. Biological Invasions 22: 1997-2016.

Funk JL. 2013. The physiology of invasive plants in low-resource environments. Conservation Physiology 1: cot026. doi: 10.1093/ conphys/cot026

Giulietti AM, Menezes NL, Pirani JR, et al. 1987. Flora da Serra do Cipó, Minas Gerais: caracterização e lista das espécies. Boletim de Botânica da Universidade de São Paulo 9: 1-151.

Grime JP. 2001. Plant strategies, vegetation processes, and ecosystem properties. 2nd. edition. Chichester, UK, Wiley \& Sons.

Gurevitch J, Fox GA, Wardle GM, et al. 2011. Emergent insights from the synthesis of conceptual frameworks for biological invasions. Ecology Letters 14: 407-418.

Hopper SD, Lambers H, Silveira FAO, Fiedler PL. 2021. OCBIL theory examined: reassessing evolution, ecology and conservation in the world's ancient, climatically buffered and infertile landscapes. Biological Journal of the Linnean Society 133: 266-296.

Kichenin E, Wardle DA, Peltzer DA, et al. 2013. Contrasting effects of plant inter-and intraspecific variation on community-level trait measures along an environmental gradient. Functional Ecology 27: 1254-1261.

Mannetje LT. 1977. A revision of varieties of Stylosanthes guianensis (Aubl.) Sw. Australian Journal of Botany 25: 347-362. 
Negreiros D, Le Stradic S, Fernandes GW, et al. 2014. CSR analysis of plant functional types in highly diverse tropical grasslands of harsh environments. Plant Ecology 215: 379-388.

Palacio-López K, Gianoli E. 2011. Invasive plants do not display greater phenotypic plasticity than their native or non-invasive counterparts: a meta-analysis. Oikos 120: 1393-1401.

De Paula LF, Negreiros D, Azevedo LO, et al. 2015. Functional ecology as a missing link for conservation of a resource-limited flora in the Atlantic forest. Biodiversity and Conservation 24: 2239-2253.

Pérez-Harguindeguy N, Díaz S, Garnier E, et al. 2013. New handbook for standardised measurement of plant functional traits worldwide. Australian Journal of Botany 61: 167-234.

R Development Core Team. 2019. R: A language and environment for statistical computing. R Foundation for Statistical Computing, Vienna, Austria. https://www.R-project.org/. 01 Dec. 2019.

Reich PB. 2014. The world-wide 'fast-slow' plant economics spectrum: a traits manifesto. Journal of Ecology 102: 275-301.

Rejmánek M. 2000. Invasive plants: approaches and predictions. Austral Ecology 25: 497-506.

Richards CL, Bossdorf O, Muth NZ, et al. 2006. Jack of all trades, master of some? On the role of phenotypic plasticity in plant invasions. Ecology Letters 9: 981-993.

Santos R, Citadini-Zanette V, Leal-Filho LS, et al. 2008. Spontaneous vegetation on overburden piles in the coal basin of Santa Catarina, Brazil. Restoration Ecology 16: 444-452.
Seabloom EW, Borer ET, Buckley YM, et al. 2015. Plant species' origin predicts dominance and response to nutrient enrichment and herbivores in global grasslands. Nature Communications 6: 7710. doi: $10.1038 /$ ncomms 8710

Silveira FAO, Barbosa M, Beiroz W, et al. 2019. Tropical mountains as natural laboratories to study global changes: a long-term ecological research project in a megadiverse biodiversity hotspot. Perspectives in Plant Ecology, Evolution and Systematics 38: 64-73.

Silveira FAO, Negreiros D, Barbosa NPU, et al. 2016. Ecology and evolution of plant diversity in the endangered campo rupestre: a neglected conservation priority. Plant and Soil 403: 129-152.

Siniscalco C, Barni E. 2017. Are Non-native Plant Species a Threat to the Alps? Insights and Perspectives. In: Pedrotti F. (ed.) Climate Gradients and Biodiversity in Mountains of Italy. Geobotany Studies (Basics, Methods and Case Studies). Cham, Springer. p. 91-107.

Sultan SE. 2001. Phenotypic plasticity for fitness components in Polygonum species of contrasting ecological breadth. Ecology 82: 328-343.

Tecco PA, Díaz S, Cabido M, et al. 2010. Functional traits of alien plants across contrasting climatic and land-use regimes: do aliens join the locals or try harder than them? Journal of Ecology 98: 17-27.

Waddell EH, Chapman DS, Hill JK, et al. 2020. Trait filtering during exotic plant invasion of tropical rainforest remnants along a disturbance gradient. Functional Ecology 34: 2584-2597.

Wickham H. 2016. ggplot2: Elegant graphics for data analysis. New York, Springer-Verlag. 